\title{
Why not Seek Therapy? The Role of Stigma and Psychological Symptoms in College Students
}

\author{
Makilim Nunes Baptista ${ }^{1}$ \\ Universidade São Francisco, Itatiba-SP, Brazil
}

\author{
Cristian Zanon \\ Universidade São Francisco, Itatiba-SP, Brazil
}

\begin{abstract}
The decision to seek therapy can reduce psychological distress and factors like public stigma, self stigma, fear of self exposure to therapist, among others, may constitute barriers in this process. This study investigated: how is the group of variables described in the literature as predictors of seeking therapy, and the relationship of variables associated with stigma and depressive symptoms, anxiogenic symptoms and stress with this search. For this purpose, 272 students responded scales that assessed these variables. The principal component analysis indicated four clusters of variables (symptoms of depression, anxiety and stress; feelings of shame, inadequacy and inhibition; perception of benefits to seek therapy; self stigma and stigma by the others). These components are hierarchically inserted into the multiple regression, indicating that the symptoms have little importance compared to the attitude of seeking therapy and stigmas.
\end{abstract}

Keywords: psychotherapy, mental health, symptoms, coping behavior, stigma

\section{Por Que Não Buscar Terapia? O Papel do Estigma e Sintomas Psicológicos em Universitários}

\begin{abstract}
Resumo: A decisão por buscar terapia pode reduzir o sofrimento psicológico e fatores como estigma público, autoestigma, medo da autoexposição ao terapeuta, dentre outros, podem constituir barreiras neste processo. Este estudo investigou como ocorre o agrupamento de variáveis descritas na literatura como preditoras de busca por terapia, e a relação das variáveis associadas à estigmatização e de sintomas depressivos, ansiogênicos e de estresse com essa busca. Para isto 272 universitários responderam escalas que avaliavam estas variáveis. A análise de componentes principais indicou quatro agrupamentos de variáveis (sintomas de depressão, ansiedade e estresse; sentimentos de vergonha, inadequação e inibição; percepção de benefícios ao buscar terapia; auto e hetero estigmas). Estes componentes foram hierarquicamente inseridos na regressão múltipla indicando que a sintomatologia é pouco relevante se comparada à atitude de busca por terapia e os estigmas.
\end{abstract}

Palavras-chave: psicoterapia, saúde mental, sintomas, enfrentamento, estigma

\section{¿Por Qué No Buscar la Terapia? El Papel de Estigma y Síntomas Psicológicos en Universitarios}

\begin{abstract}
Resumen: Buscar la terapia puede reducir la angustia psicológica y factores como el estigma público, auto-estigma, miedo de la auto-exposición a la terapeuta, entre otros, pueden constituir barreras en este proceso. Este estudio investigó: cómo ocurre el agrupamiento de variables descritas en la literatura como predictores de la búsqueda de la terapia, y la relación de variables asociadas con el estigma y los síntomas depresivos, ansiogénicos y el estrés con esta búsqueda. Para este propósito, 272 estudiantes contestaron escalas que evaluaron estas variables. El análisis de componentes principales indicó cuatro grupos de variables (síntomas de la depresión, la ansiedad y el estrés, sentimientos de vergüenza, insuficiencia y la inhibición, la percepción de los beneficios que buscan terapia, de auto y hetero estigmas). Estos componentes fueron jerárquicamente insertan en la regresión múltiple, que indica que los síntomas son de poca importancia en comparación con la actitud de buscar terapia y estigmas.
\end{abstract}

Palabras clave: psicoterapia, salud mental, síntomas, enfrentamiento, estigma

The search for mental health professionals can represent an important gain for people in mental suffering. Patients being treated can present symptom relief and develop efficient strategies to cope with problems and develop their potential (Layous, Chancellor, \& Lyubomirsky, 2014), if the therapy is successful. Therefore, the search for professionals who can help seems to be an unquestionable decision for people who

\footnotetext{
${ }^{1}$ Correspondence address:

Makilim Nunes Baptista. Universidade São Francisco, Campus Swift. Rua Waldemar César da Silveira, 105. Jd. Cura D’Ars. CEP 13045-510. Campinas-SP, Brazil
}

are suffering. Many individuals, in the model by Eisenberg, Downs, Golberstein and Zivin (2009), adopt the following order of events: (1) experience health problems, often associated with suffering; (2) perceive the need to seek professional help; (3) assess the costs and benefits of getting treatment (considering the social/cultural context) and (4) mobilize to choose some type of help.

Nevertheless, the sequence described above does not always take place. One might think that, the greater the suffering, the stronger the inclination to seek a therapist. Therefore, people in little suffering may simply not seek help because 
they believe that they can solve their problems alone or because they do not believe that the therapy can produce the expected result. Despite this series of plausible possibilities, evidences indicate that therapy-associated stigma can be the most important factor not to seek therapy (Vogel, Heimerdinger-Edwards, Hammer, \& Hubbard, 2011; Vogel, Shechtman, \& Wade, 2010; Vogel, Wade, \& Ascheman, 2009). In addition, evidences indicate that attitudes, beliefs, expectations, among other variables, can be associated with the process of seeking therapeutic help (Cheng, Kwan, \& Sevig, 2013; Rojas-Vilches, Negy, \& Reig-Ferrer, 2011).

Stigma, characterized by a set of negative perceptions, has been indicated as one of the most relevant inhibitors of the search for therapeutic help (Corrigan, 2004). In this case, the stigma can be divided in two types: the public and the self-stigma. The public stigma would be the perception by a group or society that an individual is socially unacceptable which produces negative reactions, by society, towards him. Self-stigma, then, occurs when the individual engenders the perception that his characteristics (e.g., depression, anxiety, stress) are socially inadequate and that he can be labeled for being in that condition (Corrigan, 2004).

Other factors can also affect the decision to seek help in case of psychological problems (Pheko, Chilisa, Balogun, \& Kgathi, 2013). Beliefs on devaluation and discrimination about getting treatment (Link, Cullen, Frank, \& Wozniak, 1987), attitudes towards the search for professional help (Fischer \& Farina, 1995), intention to request counseling (Cash, Begley, McCown, \& Weise, 1975), quality and proximity of interpersonal relationships (Cross, Bacon, \& Morris, 2000), form of coping with possible losses (Zane, 2000), personal disclosure expectations and tolerance of deviant behaviors (Gelfand et al., 2011) can be associated with the search for professional help. Besides these variables, we conjecture that the level (frequency and intensity) of psychopathological symptoms can be a variable directly related with the search for help (Golberstein, Eisenberg, \& Gollust, 2008).

Investigating inhibiting factors of the search for therapy can be fundamental to elaborate strategies that enhance the chances of connection between therapists and future patients (Wade, Post, Cornish, Vogel, \& Tucker, 2011). Through this study, we intend to contribute to the understanding of the existing gap between mental suffering and seeking a therapist for psychological treatment.

Evidences indicate that the stigma of receiving psychotherapeutic treatment represents an important impediment for (not) seeking treatment (Corrigan, 2004), as society can see the people who get treatment as less confident, interesting and more emotionally unstable (Sibicky \& Dovidio, 1986). In addition, people can avoid starting treatment so as not to suffer self-stigma for being under psychological treatment. That is, besides the social stigma, the subject himself can present a negative attitude towards himself to start a treatment (Corrigan, 2004).

As presented earlier, the stigma can prevail over the symptoms and, therefore, inhibit the search for treatment. Nevertheless, the number and intensity of the symptoms can characterize a relevant aspect to seek treatment. To give an example: a patient who suffers intensely can consider that the search for therapeutic help represents an important gain, and consequently compensate for the possible losses deriving from different types of stigma and self-exposure. In that sense, the level of suffering can be a determining factor of the search for therapy. In other words, in view of important symptoms of depression, anxiety and stress, among others, the decision to seek help may be influenced by the levels of suffering people's psychopathologies cause.

Therefore, we believe that investigating factors that negatively influence the search for therapy (e.g., self-stigma, social stigma, among others) should consider the level of the participants' symptoms as a whole. We found no studies that assessed the relations of different types of stigma in the search for therapy, controlling for the participants' levels of depression, anxiety and stress. The bases PsychINFO and Web of Science were consulted. It is possible, for example, that depression inhibits the search for therapy more than other disorders involving symptoms of stress and anxiety. In that sense, Baptista (2004) appoints that symptoms like social isolation and reduced self-esteem can characterize explanatory factors that reduce the search for help. In this study, we intended to assess the relevance of a series of factors related to different types of stigma, in combination with stress, depression and anxiety symptoms, in the intent to seek therapeutic help. More specifically, we intend to: (a) assess how different types of stigma are grouped, and (b) the contribution of stress, depression and anxiety symptoms in predicting the search for therapy, in combination with the set of variables related to different types of stigma.

\section{Method}

\section{Participants}

The participants were 275 college students (mean age $=$ 24.5; $S D=6.1$ years) from Psychology courses (81.6\% from the Southeast and $19.4 \%$ from the Northeast), being $81.2 \%$ female and $52.5 \%$ from private institutions, characterized as a convenience sample.

\section{Instruments}

All instruments presented evidence of validity and reliability for this study. The alpha coefficients obtained in the sample are indicated under the description of each instrument and the remaining adaptation procedures are described in the data collection procedure.

Stigma Scale for Receiving Psychological Help - SSR$P H$. Five-item self-reported instrument $(\alpha=.71)$ rated on a four-point Likert scale ( $1=I$ totally disagree, $2=I$ disagree, $3=$ I agree 4, = I totally agree) assessing the stigma related to receiving psychological help (Komiya, Good, \& Sherrod, 2000). Examples of items are: "Seeing a psychologist for emotional or interpersonal problems carries a social stigma" and "Seeing a psychologist for emotional or interpersonal problems is a sign of personal weakness or inadequacy".

Beliefs in Devaluation/Discrimination Scale - BDDS. 
Twelve-item self-reported instrument $(\alpha=.82)$ rated on a six-point Likert scale ( $1=I$ totally disagree, $2=I$ disagree, $3=I$ slightly disagree, $4=I$ slightly agree, $5=I$ agree, $6=I$ totally agree) that assess beliefs about the acceptance or devaluation of people submitted to psychotherapeutic treatments (Link et al., 1987). This scale includes items like "Most people believe that a person who was in a psychiatric hospital is as intelligent as a normal person" and "Most young women would be reluctant to date a man who was hospitalized due to a severe mental disorder".

Perceived Stigma of Others to Seek Psychological Help - PSOSPH. Five-item instrument $(\alpha=.85)$ rated on a five-point Likert scale $(1=$ Not at all, $2=$ Somewhat, $3=$ More or less, $4=A$ lot, and $5=$ Very $m u c h)$, which assess family hetero-stigma to seek psychological help (Vogel et al., 2009). This scale consists of items about which the individual thinks the family members would assess him if he sought professional help. Examples of items are: "Consider that you are severely disturbed" and "Thinking less positively about you".

Self-Stigma of Seeking Help Scale - SSOSH. Ten-item instrument $(\alpha=.73)$ rated on a five-point Likert scale $(1=I$ totally disagree, 2 = I disagree, $3=$ I equally agree/disagree, $4=$ I agree, and $5=$ I totally agree) that assess how the individual would react to the need to seek psychological help to cope with problems (Vogel, Wade, \& Hackler, 2007). Some examples of items are: "I would feel inadequate if I went to a therapist for psychological help" and "Seeking psychological help would make me feel less intelligent".

Self-Stigma of Depression Scale - SSDS. 16-item instrument $(\alpha=.90)$ rated on a five-point Likert scale $(1=$ I totally disagree, 2 =I disagree, $3=$ Ineither agree nor disagree, $4=$ I agree, 5 = I totally agree) that assess thoughts and feelings about the presence of a mental illness in oneself (adapted from Barney, Griffiths, Jorm, \& Christensen, 2006). This scale can be used in one dimension or in facets: shame, self-blame, social inadequacy and help-seeking inhibition. This scale was modified for this study and, instead of depression, the heading presents mental illness as the topic. Examples of items are "I would feel like a burden to other people" and "I would feel inadequate around other people".

Attitudes towards Search for Professional Psychological Help - short version - ATSPPH. Ten-item instrument $(\alpha$ $=.66)$ rated on a four-point Likert scale $(0=I$ disagree, $1=I$ probably disagree, $2=$ I probably agree, $3=$ I agree) that assess thoughts and behaviors concerning the intent to seek help from a mental health professional (Fischer \& Farina, 1995). Some items on this scale are "I would like to get psychological help if I were concerned or upset over a long period of time" and "A person should solve his/her own problems, getting psychological counseling as a last resource".

Intent to Seek Counseling Inventory - ISCI. Ten-item instrument $(\alpha=.88)$ on a six-point Likert scale $(1=$ highly improbable to $6=$ highly probable) to assess the extent to which a person would seek counseling/therapy in different situations, such as: "Depression" and "Concerns with sexuality" (Cash et al., 1975). For this study, only the interpersonal and psychological subscales were used.

Relational Self-Concept Scale - RSCS. 11-item instru- ment $(\alpha=.81)$ rated on a seven-point Likert scale (ranging from I strongly disagree 1 to I strongly agree 7 ), assessing the quality and proximity of interpersonal relationships (Cross et al., 2000). Some examples of items are "My intimate relationships are an important reflection of who I am" and "When I feel very close to someone, it often seems that that person is an important part of me".

Loss of Face Scale - LLS. 21-item instrument $(\alpha=.83)$ rated on a six-point Likert scale (ranging from I totally disagree 1 to I totally agree 7), assessing elusion from situations that can threaten the social integrity (Zane, 2000). Examples of items are "I feel more affected when someone criticizes me in public than when someone criticizes me in private" and "During a debate, I try not to ask questions because I may look ignorant to others".

Scale of Depression, Anxiety and Stress - DASS-21. Instrument consisting of three factors (depression, stress and anxiety) and 21 items $(\alpha=.91)$ rated on a four-point Likert scale (ranging from does not apply to me at all 1 to greatly applies to me, or most of the time 4), which assess symptoms of depression, anxiety and stress (Henry \& Crawford, 2005; S.H. Lovibond \& P.F. Lovibond, 1995). Examples of items are "I faced difficulties to calm down", "I felt my mouth was dry" and "I felt that there was nothing to expect for the future".

Disclosure Expectations Scale - DES. Eight-item tool $(\alpha=.56)$ rated on a five-point Likert scale (ranging from not at all 0 to a lot 4 ), assessing the extent to which the person feels discomfort or benefit as a result of the disclosure of personal information to health professionals, being called DesRisk and DesBen, respectively (Vogel \& Wester, 2003). Examples of items are "How difficult would it be for you to reveal personal information to an counselor?" and "How useful would it be to reveal a personal problem to a counselor?".

Tightness-Looseness Scale - TLS. Six-item instrument $(\alpha=.63)$ rated on a six-point Likert scale (ranging from I strongly disagree 1 to I strongly agree 6), assessing behaviors towards standards and low tolerance of deviant behaviors (Gelfand et al., 2011). Examples of items are "There are many social standards the people supposedly accept to comply with in this country" and "The people in this country have a great deal of freedom to decide on how they want to behave in most situations (inverted)".

Internalized Self-Face Scale (ISFS). A measure of self-perception related to what others think about performance, self-image and receiving external criticism. Vogel et al. (2009) developed this scale for the purpose of this study ( $\alpha$ $=.82$ ), aiming to assess the person's overall self-perception towards others. This instrument consists of six items rated on a five-point Likert scale (ranging from very imprecise 1 to very precise 6). Examples of items are "I am concerned with what others think of me", "I don't want to give a bad impression in front of others" and "I am sensitive to the way others criticize me".

\section{Procedure}

Data collection. The instruments were translated and adapted to Portuguese by two bilingual psychologists with 
expertise in the adaptation of psychological tests and assessment. In addition, factor analyses were applied to assess the internal structure of all instruments used in this study. The reliability was verified by means of the alpha coefficient, also checking evidences of validity for all instruments. In addition, all instruments demonstrated measurement invariance (same structure and similar factor loadings) in relation to the original American instruments (D.L. Vogel, personal correspondence, March 15 $\left.{ }^{\text {th }} 2015\right)$. The tests were posted on the online platform Google docs and made available to the participants by telephone and e-mail contact with professors from different universities in Brazil, aiming to encourage the students to participate in the research. The time spent to complete the questionnaires was not controlled for, as the software does not consider this type of parameter.

Data analysis. To investigate the objectives proposed in this research, principal component analysis was applied, as well as a variance prediction analysis based on some clusters of relevant indicators (multiple hierarchical regression analysis - enter method). This method was chosen because it covers all variables wanted in the model. Both analyses were undertaken in statistical software SPSS version 19.

\section{Ethical Considerations}

Approval for this research was obtained from Iowa State University on February $15^{\text {th }} 2012$ under number 12015 , entitled Self Stigma Research Collaborative, being part of an international multicenter research carried out in the United States, Canada, United Kingdom, Portugal, Brazil, Taiwan, Lithuania, Romania, Turkey, Australia, Hong Kong and United Arab Emirates. The data presented here only refer to the data collection in Brazil, registered in the CEP under CAAE: 0422.0.142.00-11 at Universidade São Francisco.

\section{Results}

\section{Principal Component Analysis}

Initially, all variables were submitted to a principal component analysis with oblimin rotation to assess the clustering pattern of important predictors of the intent to seek psychological counseling. Five components were extracted with eigenvalues superior to 1 , but this solution did not seem clear theoretically and indicated that some predictors presented loadings that were either double or inferior to .30 . As the scree plot indicated four components, this solution was assessed next and the structure observed was in line with theoretical expectations, with only three items presenting low factor loadings. Items with component loadings inferior to .50 were removed and a new analysis with the extraction of four components revealed the structure adopted in this research (Table 1). It is highlighted that the removal of these variables was also based on the theoretical overlapping found with other variables that were maintained. In this model, $\mathrm{KMO}=.77$ was identified, a significant Bartlett test and eigenvalues explaining $59.87 \%$ of the total variance. A three-component solution was tested but was not theoretically coherent and was therefore discarded.
Table 1

Final Principal Component Analysis of the Set of Variables Selected to Predict the Search for Psychological Help

\begin{tabular}{cccc}
\hline \multirow{2}{*}{ Variables } & \multicolumn{3}{c}{ Components } \\
\cline { 2 - 4 } PSOSPH & 1 & 2 & 3 \\
\hline DASS-Depression & - & .815 & - \\
DASS-Anxiety & - & .863 & - \\
DASS-Stress & - & .839 & - \\
ATSPH & - & - & .573 \\
RSCS & - & - & .493 \\
LLS & .528 & - & - \\
DES-Risk & .466 & - & - \\
DES-Benefit & - & - & .756 \\
BDDS & - & - & - \\
SSRPH & - & - & - \\
SSDS-Shame & .842 & - & - \\
SSDS-Self-blame & .645 & - & - \\
SSDS-Social inadequacy & .744 & - & - \\
SSDS-Help-seeking inhibition & .765 & - & - \\
SSOSH & - & - & .520 \\
ISFS & .519 & - & - \\
Eigenvalue & 3.52 & 2.13 & 1.47 \\
\% variance & 25.12 & 15.18 & 10.51 \\
\hline
\end{tabular}

Note. DASS $=$ Depression, Anxiety Stress Scale; PSOSPH $=$ Perceived Stigma of Others to Seek Psychological Help, ATSPPH = Attitudes towards Search for Professional Psychological Help, RSCS $=$ Relational Self-Concept Scale, LLS $=$ Loss of Face Scale, DESRisk: Expected risk of exposure, DES-Benefit $=$ Expected benefit of exposure, BDDS = Beliefs in Devaluation/Discrimination Scale, SSRPH $=$ Stigma Scale for Receiving Psychological Help, SSDS = Self-stigma of Depression Scale; SSOSH = Self-Stigma of Seeking Help Scale; ISFS = Internalized Self-Face Scale.

\section{Multiple Hierarchical Regression}

The set of variables grouped in the principal component analysis was used to predict the intention to seek psychological counseling. Therefore, a hierarchical regression model was executed that consisted of four steps (enter method). Each step included one of the components extracted in the previous analysis (Table 2). This analysis is intended to assess the proportion of specific variance each cluster adds to the model. In the first step of the regression, component two was inserted, that is, the cluster of variables related to depression, anxiety and stress symptoms. In the second step, component one was inserted, with variables related to feelings of shame, social inadequacy and help-seeking inhibition. In the third step, component three was inserted, which consists of variables that assess the benefits the participant will perceive in seeking therapy, the attitude towards the search for therapy and the self-representation of the relationships constructed in the therapeutic setting. Finally, in the fourth step, component four was inserted, which contains variables that indicate self and hetero-stigma towards receiving psychological help. As ob- 
served in Table 2, four variables were statistically significant in the final model (step 4). Considering the decreasing order of the Beta, which represents the standardized regression coefficient, it was verified that the attitude towards the search for professional psychological help presented the highest coefficient, followed by the expected benefit of exposure; the quality and proximity of the interpersonal relationships and, finally, the expected risks of exposure.

Table 2

Final Regression Model (Step 4) With Selected Variables to Predict Intention to Seek Counseling (Enter Method)

\begin{tabular}{|c|c|c|c|}
\hline Variables & $\beta$ & $\mathrm{t}$ & $\mathrm{p}$ \\
\hline DASS-Depression & .089 & .976 & .330 \\
\hline DASS-Anxiety & -.073 & -.817 & .415 \\
\hline DASS-Stress & .136 & 1.489 & .138 \\
\hline LLS & .066 & .805 & .422 \\
\hline DES-RISK & -.139 & -1.926 & .056 \\
\hline SSDSS-Social inadequacy & .051 & .488 & .626 \\
\hline SSDS-Help-seeking inhibition & -.034 & -.451 & .653 \\
\hline SSDS-Shame & -.101 & -1.151 & .251 \\
\hline SSDS-Self-blame & -.023 & -.254 & .800 \\
\hline ISFS & .115 & 1.506 & .134 \\
\hline ATSPH & .272 & 3.770 & .000 \\
\hline RSCS & .148 & 2.186 & .030 \\
\hline DES-BENEFIT & .190 & 2.591 & .010 \\
\hline SSoSH & .013 & .189 & .850 \\
\hline PSOSPH & -.054 & -.763 & .446 \\
\hline BDDS & .093 & 1.325 & .187 \\
\hline SSRPH & .088 & 1.210 & .228 \\
\hline
\end{tabular}

Note. DASS: Depression, Anxiety Stress Scale; PSOSPH $=$ Perceived Stigma of Others to Seek Psychological Help, ATSPPH = Attitudes towards Search for Professional Psychological Help, RSCS $=$ Relational Self-Concept Scale, LLS $=$ Loss of Face Scale, DESRisk $=$ Expected risk of exposure, DES-Benefit $=$ Expected benefit of exposure, BDDS = Beliefs in Devaluation/Discrimination Scale, SSRPH $=$ Stigma Scale for Receiving Psychological Help, SSDS = Self-stigma of Depression Scale; SSOSH = Self-Stigma of Seeking Help Scale; ISFS: Internalized Self-Face Scale.

As observed in Table 3, step 1 predicted approximately $3.1 \%$ of the variance in the criterion variable $[F(3)=1.9 ; p$ $<$.12]. Step 2 explained $12.9 \%$ of exclusive variance $[F(10)$ $=3.7 ; p<.001]$. Step 3 added little exclusive variance to the model (only 1.7\%), although significant $[F(14)=5.8 ; p<$ $.001]$, while step 4 added $15.1 \%$ of variance to the model $[F$ $(17)=5.0 ; p<.001]$. Overall, these results suggest that psychopathological symptoms have a much weaker role in the search for psychological help than beliefs on the treatment and the associated stigma.
Table 3

Regression Model Using the Intention to Seek Psychological Counseling as a Criterion Variable and Psychopathological Symptoms, Attitudes and Stigma as Predictors

\begin{tabular}{ccc}
\hline Step & $R$ & $R^{2}$ \\
\hline 1 & $.176^{\mathrm{a}}$ & .031 \\
2 & $.400^{\mathrm{b}}$ & .160 \\
3 & $.421^{\mathrm{c}}$ & .177 \\
4 & $.572^{\mathrm{d}}$ & .328 \\
\hline
\end{tabular}

Note. a. Predictors = DASS-Stress, DASS-Depression, DASS-Anxiety; b. Predictors: DASS-Stress, DASS-Depression, DASS-Anxiety, SSDS-Self-blame, ISFS, DES-RISK, SSDS-Social inadequacy, LLS, SSDSHS-Help-seeking inhibition, SSDS-Shame; c. Predictors = DASS-Stress, DASS-Depression, DASS-Anxiety, SSDS-Self-blame, ISFS, DES-RISK, SSDS-Social inadequacy, LLS, SSDSHS-Help-seeking inhibition, SSDS-Shame, BDDS, PSOSPH, SSRPH; d. Predictors = DASS-Stress, DASS-Depression, DASS-Anxiety, SSDS-Self-blame, ISFS, DES-RISK, SSDS-Social inadequacy, LLS, SSDSHS-Help-seeking inhibition, SSDS-Shame, BDDS, PSOSPH, SSRPH-Reviewed, RSCS, ATSPH, DES-Benefit.

\section{Discussion}

In this study, we intended to assess the factors that influence the search for psychotherapeutic help, more specifically how factors related to different kinds of stigma can inhibit the intent to seek a health professional. In that sense, the different variables used in the study were clustered to understand how important predictors of the intent to seek therapy are mutually related (Vogel et al., 2007). Based on this cluster, a multiple hierarchical regression analysis was undertaken to verify the most relevant variables in the prediction of the search for health professionals. This analysis permits assessing the extent to which each cluster of variables contributes to predict the dependent variable (Schafer, 1991).

Initially, it was verified that the clustering of the variables in four factors explained approximately $60 \%$ of the total variance, indicating that few components were necessary to explain the variance of 17 relevant variables, each contributing differently. It is highlighted that few variables were eliminated in this first analysis phase due to their empirical relationship with the others. This may have been due to the lack of variation in these variables at, theoretically, moderate relations should exist with the other variables. Variables like devaluation beliefs and stigma to receive help, for example, did not load in the factor analysis in this first analysis.

Although distinct, the sets of variables inserted in the four steps of the model represent theoretically relevant clusters. To give an example, the first component clustered variables related to feelings of shame, help-seeking inhibition, social inadequacy and self-blame in the search for psychological help. Evidences indicate that this cluster of variables is common in individuals who consider the search for help in the belief that seeking therapy is only for people with severe disorders (Parcover, Dunton, Gehlert, \& Mitchell, 2006). The second component grouped symptoms of psychopathology related to depression, anxiety and stress. The symptoms 
of these disorders are frequently associated - characterizing diagnoses of comorbidities (Baptista, 2012). The third component clustered variables regarding the benefits and attitudes of seeking therapeutic help, besides the quality and proximity of the interpersonal relationships. This cluster is in accordance with the study by Bathje and Pryor (2011), in which it was verified that attitudes towards the search for therapy constitute important and mutually associated predictors of the search for therapy. Finally, the fourth factor grouped variables related to the perceived stigma by others, devaluation and discrimination beliefs. This cluster is in accordance with the findings by Phelan, Link, Stueve and Pescosolido (2000), which evidenced that mental illness is not only associated with high public stigmatization scores, but also with a less reliable, interesting and competent opinion (Ben-Porath, 2002).

The regression model indicated that the four clusters of variables, selected through principal component analysis, contributed to predict the search for therapy - although some contributed with greater predicted variance in the model than others. In addition, among the 17 variables in the course of the model, only four remained significant in the final model, which are: attitude towards the search for help, the benefits and risk the search can offer, and the quality and proximity of the interpersonal relationships. Based on the interpretation of the Beta coefficients, one might think, in practical terms, that the attitude towards seeking professional psychological help was the most important predictor of the intention to seek help. In that sense, the individual's belief in the competence of psychological science and the psychotherapist to actually help and solve the problem presented seems to be critical to seek psychotherapeutic help (Vogel et al., 2007).

This result indicates that interventions to increase the search for therapy should focus on the development of a positive attitude in the search of therapy. One could emphasize that: "normal people go through different kinds of difficulties that can be very difficult to cope with sometimes" (Neff, 2012). That does not mean that the person is less reliable, competent or interesting; it is but the context of a set of momentarily unfavorable factors. In that sense, some external person (e.g., the therapist) could reduce the suffering and the length of recovery of normal people going through momentary difficulties.

Next, it was observed that the importance of the benefits the individual believes to gain from the intervention is another relevant variable in the model. In other words, the extent to which the revelation of thoughts and feelings about the personal problems can be useful to relief the symptoms presented. Komiya et al. (2000) indicate that the search for psychotherapeutic treatment depends on the individuals' emotional opening, who should believe that their self-exposure can offer gains. The third significant variable in the model is the good quality and proximity of the affective and support relationships, indicating that people with more qualitative affective relationships (e.g., greater social support) feel more secure to seek help (Street, Makoul, Arora, \& Epstein, 2009). These findings suggest that disclosing the importance of psychotherapy together with family support and encouragement can play a decisive role in the search for therapy.

The final variable is related to the set of risks associa- ted with the exposure of intimate thoughts and feelings to the therapist, that is, the fear of exposing personal issues to the psychotherapist, in the sense of finding oneself vulnerable and afraid of talking about the theme with the psychotherapist without getting some gain out of this exposure (Vogel \& Wester, 2003). This result suggests that practices that explain the secrecy and confidentiality of patient care need to be encouraged and that the need to address intimate personal aspects is important to appropriately understand the case. Thus, psychotherapeutic intervention can be more efficient and the patient can get further gains from the therapy.

Another relevant finding in the results refers to the extent to which the four clusters of variables (negative feelings towards the search for help, psychopathological symptoms, benefits of the search for help and self/hetero-stigma for seeking help) explain the intent to seek professional help. Against expectations, but possibly related to the specificity of the sample, the association between the intensity of the set of psychopathological symptoms and the intention to seek help was weak. Different results were found in the study by Vogel and Wei (2005), which indicated that increased stress is associated with greater chances of seeking professional care. It is important to highlight that this sample presented low levels of depression symptoms $(M=$ $0.72 ; S D=0.63)$, anxiety $(M=0.43 ; S D=0.49)$ and stress $(M$ $=1.11 ; S D=0.66$ ), indicating low psychological suffering and data variability. Perhaps, in clinical samples with greater variability, the psychological suffering could play a more important role in the search for treatment.

Differently from the psychopathological symptoms, the negative feelings predicted a considerable part of the variance in the search for treatment. This indicates that feelings related to shame, self-blame, help-seeking inhibition and social inadequacy play an important role in not seeking help (Vogel $\&$ Wester, 2003). One of the hypotheses behind this result is that people with these characteristics present greater difficulties in interpersonal relationships and, being therapy a form of intimate relationship, their treatment search is expected to be less intense.

The third group of variables, called benefits of the search for help, predicted little exclusive variance (beyond the variance the previous predicators explained) of the search for help. This means that, although important for the treatment search, the feeling that psychotherapy can offer great benefits to the individual is not paramount to seek help. This interpretation can be relevant to the extent that the inclusion of the fourth cluster of variables, called self/hetero-stigma, explains about twice as much of the exclusive variance as the first three clusters. The importance of stigma for not seeking treatment represents a great obstacle that requires the planning of actions regarding the disclosure of treatments and the re-education of the beliefs on factors associated with the therapy and mental illness (Kaplan, Vogel, Gentile, \& Wade, 2012).

It is important to mention that none of the studies found in the review used that many variables in a hierarchical regression model to predict the search for professional help. To give an example, in a study of college students that assessed some of the variables in this research, Vogel et al. (2007) found that self-stigma and attitude towards the search for profes- 
sional help were the most important predictors of the intention to seek help - in line with our results.

One of the limitations in this study is the sample used, as psychology students were the majority. This can bias the results, as these people may have lower levels of self-stigma towards the search for psychological interventions, greater intent to seek counseling, greater self-exposure of their problems and, consequently, having relatives and friends with less stigma towards the search for psychological/psychiatric help. Another limitation relates to the non-control of psychiatric disorders in the sample and the low levels of depression, anxiety and stress symptoms, which probably influenced the weak relation with the intent to seek help.

The negative perception of what others will think of the individual when (s)he seeks help played a fundamental role in not seeking treatment. Nevertheless, the prejudice itself towards getting treatment is also part of this explanation. Reducing the social stigma associated with mental illness and the search for help would be one way to enhance the search for health services and professionals, with a view to decreasing many people's psychological suffering (Vogel et al., 2009). Future studies can try to assess whether psychology students, more than students from other courses, have the feeling that they do not need therapeutic help because they are studying the human problems (Thomas, Caputi, \& Wilson, 2014). In terms of increasing the probability of therapeutic search, programs should be developed to raise awareness on and disseminate the importance of psychotherapy to relieve suffering and solve problems.

Finally, it can be important to verify other variables in future studies, such as the individuals' social and family support, in order to check their role in the search for treatment and the reduction of self and hetero-stigma. Besides these variables, it can be relevant to assess each person's knowledge on the role of a psychologist, if (s)he has done psychotherapy before and his/ her level of satisfaction with the professionals, and even socioeconomic conditions to get access to a professional psychologist.

\section{References}

Baptista, M. N. (2004). Psicoterapias cognitivo-comportamental e cognitiva: Aspectos teóricos e terapêuticos no manejo de depressão e suicídio [Cognitive and cognitive-behavioral therapies: Theory and treatment for depression and suicide] In M. N. Baptista (Org.), Suicídio e depressão: Atualizações [Updates in suicide and depression] (pp. 161-176). Rio de Janeiro, RJ: Guanabara-Koogan.

Baptista, M. N. (2012). Escala Baptista de Depressão: Versão adulto (EBADEP-A): Manual técnico [Baptista Depression Scale: Adult version (EBADEP-A): Technical manual]. São Paulo, SP: Vetor.

Barney, L. J., Griffiths, K. M., Jorm, A. F., \& Christensen, H. (2006). Stigma about depression and its impact on help-seeking intentions. Australian and New Zealand Journal of Psychiatry, 40(1), 51-54. doi:10.1080/j. 1440-1614.2006.01741.x
Bathje, G. J., \& Pryor, J. B. (2011). The relationships of public and self-stigma to seeking mental health services. Journal of Mental Health Counseling, 33(2), 161-177. doi:10.17744/mehc.33.2.g632039274160411

Ben-Porath, D. D. (2002). Stigmatization of individuals who receive psychotherapy: An interaction between help-seeking behavior and the presence of depression. Journal of Social \& Clinical Psychology, 21(4), 400-413. doi:10.1521/jscp.21.4.400.22594

Cash, T. F., Begley, P. J., McCown, D. A., \& Weise, B. C. (1975). When counselors are heard but not seen: Initial impact of physical attractiveness. Journal of Counseling Psychology, 22(4), 273-279. doi:10.1037/h0076730

Cheng, H.-L., Kwan, K.-L., \& Sevig, T. (2013). Racial and ethnic minority college students' stigma associated with seeking psychological help: Examining psychocultural correlates. Journal of Counseling Psychology, 60(1), 98111. doi:10.1037/a0031169

Corrigan, P. W. (2004). How stigma interferes with mental healthcare. American Psychologist, 59(7), 614-625. doi:10.1037/0003-066X.59.7.614

Cross, S. E., Bacon, P. L., \& Morris, M. L. (2000). The relational- interdependent self-construal and relationships. Journal of Personality and Social Psychology, 78(4), 791808. doi:10.1037/0022-3514.78.4.791

Eisenberg, D., Downs, M. F., Golberstein, E., \& Zivin, K. (2009). Stigma and help seeking for mental health among college students. Medical Care Research and Review, 66(5), 522-541. doi:10.1177/1077558709335173

Fischer, E. H., \& Farina, A. (1995). Attitudes toward seeking professional psychological help: A shortened form and considerations for research. Journal of College Student Development, 36(4), 368-373.

Gelfand, M. J., Raver, J. L., Nishii, L., Leslie, L. A., Lun, J., Lim, B. C., ... Yamaguchi, S. (2011). Differences between tight and loose cultures: A 33-nation study. Science, 332(6033), 1100-1104. doi:10.1126/science.1197754

Golberstein, E., Eisenberg, D., \& Gollust, S. E. (2008). Perceived stigma and mental health care seeking. Psychiatric Services, 59(4), 392-399. doi:10.1176/ps.2008.59.4.392

Henry, J. D., \& Crawford, J. R. (2005). The short-form version of the Depression Anxiety Stress Scales (DASS-21): Construct validity and normative data in a large non-clinical sample. British Journal of Clinical Psychology, 44(2), 227-239. doi:10.1348/014466505X29657

Kaplan, S. A., Vogel, D. L., Gentile, D. A., \& Wade, N. G. (2012). Increasing positive perceptions of counseling: The importance of repeated exposures. The Counseling Psychologist, 40(3), 409-442. doi:10.1177/0011000011414211

Komiya, N., Good, G. E., \& Sherrod, N. B. (2000). Emotional openness as a predictor of college students' attitudes toward seeking psychological help. Journal of Counseling Psychology, 47(1), 138-143. doi:10.1037/0022-0167.47.1.138 
Layous, K., Chancellor, J., \& Lyubomirsky, S. (2014). Positive activities as protective factors against mental health conditions. Journal of Abnormal Psychology, 123(1), 3-12. doi:10.1037/a0034709

Link, B. G., Cullen, F. T., Frank, J., \& Wozniak, J. F. (1987). The social rejection of former mental patients: Understanding why labels matter. American Journal of Sociology, 92(6), 1461-1500. doi:10.1086/228672

Lovibond, S. H., \& Lovibond, P. F. (1995). Manual for the depression anxiety stress scales (2nd ed.). Sydney, Australia: Psychology Foundation.

Neff, K. D. (2012). The science of self-compassion. In C. K. Germer \& R. D. Siegel (Eds.), Wisdom and compassion in psychotherapy: Deepening mindfulness in clinical practice (pp. 79-92). New York, NY: Guilford.

Parcover, J. A., Dunton, E. C., Gehlert, K. M., \& Mitchell, S. L. (2006). Getting the most from group counseling in college counseling centers. Journal for Specialists in Group Work, 31(1), 37-49. doi:10.1080/01933920500341671

Pheko, M. M., Chilisa, R., Balogun, S. K., \& Kgathi, C. (2013, July 23). Predicting intentions to seek psychological help among Botswana university students: The role of stigma and help-seeking attitudes. Sage Open, 1-11. doi:10.1177 $/ 2158244013494655$

Phelan, J. C., Link, B. G., Stueve, A., \& Pescosolido, B. A. (2000). Public conceptions of mental illness in 1950 and 1996: What is mental illness and is it to be feared? Journal of Health and Social Behavior, 41(2), 188-207. doi:10.2307/2676305

Rojas-Vilches, A. P., Negy, C., \& Reig-Ferrer, A. (2011). Attitudes toward seeking therapy among Puerto Rican and Cuban American young adults and their parents. International Journal of Clinical and Health Psychology, 11(2), 313-341.

Schafer, W. D. (1991). Reporting hierarchical regression results. Measurement and Evaluation in Counseling and Development, 24(3), 98-100.

Sibicky, M., \& Dovidio, J. F. (1986). Stigma of psychological therapy: Stereotypes, interpersonal reactions, and the self-fulfilling prophecy. Journal of Counseling Psychology, 33(2), 148-154. doi:10.1037/0022-0167.33.2.148

Street, R. L., Jr., Makoul, G., Arora, N. K., \& Epstein, R. M. (2009). How does communication heal? Pathways linking clinician-patient communication to health outcomes. Patient Education and Counseling, 74(3), 295-301. doi:10.1016/j.pec.2008.11.015

Thomas, S. J., Caputi, P., \& Wilson, C. J. (2014). Specific attitudes which predict psychology students' intentions to seek help for psychological distress. Journal of Clinical Psychology, 70(3), 273-282. doi:10.1002/jclp.22022
Vogel, D. L., Heimerdinger-Edwards, S. R., Hammer, J. H., \& Hubbard, A. (2011). "Boys don't cry": Examination of the links between endorsement of masculine norms, self-stigma, and help-seeking attitudes for men from diverse cultural backgrounds. Journal of Counseling Psychology, 58(3), 368-382. doi:10.1037/a0023688

Vogel, D. L., Shechtman, Z., \& Wade, N. G. (2010). The role of public and self-stigma in predicting attitudes toward group counseling. The Counseling Psychologist, 38(7), 904-922. doi:10.1177/0011000010368297

Vogel, D. L., Wade, N. G., \& Ascheman, P. L. (2009). Measuring perceptions of stigmatization by others for seeking psychological help: Reliability and validity of a new stigma scale with college students. Journal of Counseling Psychology, 56(2), 301-308. doi:10.1037/a0014903

Vogel, D. L., Wade, N. G., \& Hackler, A. H. (2007). Perceived public stigma and the willingness to seek counseling: The mediating role of self-stigma and attitudes toward counseling. Journal of Counseling Psychology, 54(1), 40-50. doi:10.1037/0022-0167.54.1.40

Vogel, D. L., \& Wei, M. (2005). Adult attachment and help-seeking intent: The mediating roles of psychological distress and perceived social support. Journal of Counseling Psychology, 52(3), 347-357. doi:10.1037/00220167.52.3.347

Vogel, D. L., \& Wester, S. R. (2003). To seek help or not to seek help: The risks of self-disclosure. Journal of Counseling Psychology, 50(3), 351-361. doi:10.1037/00220167.50.3.351

Wade, N. G., Post, B. C., Cornish, M. A., Vogel, D. L., \& Tucker, J. R. (2011). Predictors of the change in self-stigma following a single session of group counseling. Journal of Counseling Psychology, 58(2), 170-182. doi:10.1037/ a0022630

Zane, N. (2000). Loss of face scale. Retrieved from: http://www. columbia.edu/cu/ssw/projects/pmap/docs/zaneloss.pdf

Makilim Nunes Baptista is a Professor in the Stricto Sen$s u$ Graduate Program in Psychology at Universidade São Francisco, Itatiba, São Paulo, Brazil.

Cristian Zanon is a Professor in the Stricto Sensu Graduate Program in Psychology at Universidade São Francisco, Itatiba, São Paulo, Brazil.

Received: June 22, 2014

1st Revision: Oct. 22, 2015

Approved: Mar. 23, 2016

How to cite this article:

Baptista, M. N., \& Zanon C. (2016). Why not seek therapy? The role of stigma and psychological symptoms in college students. Paidéia (Ribeirão Preto), 27(67), 76-83. doi: 10.1590/1982-43272767201709 